\title{
Geogebra and Grade 9 Learners' Achievement in Linear Functions
}

\author{
https://doi.org/10.3991/ijet.v14i08.9581 \\ Melody Mushipe \\ University of South Africa, Pretoria, South Africa \\ Ugorji I. Ogbonnaya( $\left.{ }^{(}\right)$ \\ University of Pretoria, Pretoria, South Africa \\ Ugorji.ogbonnaya@up.ac.za
}

\begin{abstract}
Learners' underachievement in mathematics is one major challenge in South Africa. Reports show that one of the topics that learners struggle with is functions. Many teachers also struggle to teach the topic effectively. The foundation of functions in the school mathematics curriculum is in the senior phase of schooling (Grades 7-9). Functions need to be taught effectively at the foundation level in order to ensure smooth content progression into the higher grades. Several studies globally have advocated the integration of graphing software with the teaching of some topics in mathematics including functions to enhance students' learning of the topics. This study investigated the effect of integrating GeoGebra with the teaching of linear functions on Grade 9 learners' achievement. The study was guided by the constructivist theory of learning and followed a pre-test post-test, non-equivalent groups and quasi-experimental design. The participants were 62 learners from two schools in Limpopo South Africa. The control group was 29 learners from one school and the experimental group was 33 learners from the second school. GeoGebra was integrated with the teaching in the experimental group while the control group was taught using chalk and talk. Data was collected using an achievement test and analysed using a t-test at $5 \%$ level of significance. The results showed that the experimental group $(\mathrm{M}=51.76$; SD 17.95) achieved statistically higher scores than the control group ( $M=20.00, S D 11.16)$ with a large effect of 0.53 . Implications are discussed.
\end{abstract}

Keyword-Mathematics achievement, GeoGebra, ICT, linear functions.

\section{Introduction}

A linear function is any relationship between two variables that can be drawn as a straight line. It is a fundamental topic in mathematics that finds applications in various branches of mathematics and in other subject areas, and is often utilized in real life. The learning of linear functions provides students with their first experience of identifying and interpreting the relationship between two dependent variables, which marks a significant point of transition in their mathematical development [1]. The algebraic 
representation of a linear function, often written as $\mathrm{y}=\mathrm{mx}+\mathrm{c}$, and also the graphical and tabular representations, tend to be a challenge to most students.

Improvement of mathematics education in particular is one of the major priorities of the South African government. Of particular note are the growing calls to improve the teaching and learning of mathematics in South African schools through implementation of more innovative methods of teaching, especially the integration of Information and Communication Technologies (ICT) into teaching and learning. This is particularly important in light of the unsatisfactory students' achievement in mathematics in the country over years. For example, from 2012 to 2015 the percentage of students who scored at least $40 \%$ in mathematics in the matric examination was $35.7 \%, 40.5 \%, 35.1 \%$ and $31.9 \%$ respectively in the National Senior Certificate Diagnostic Report, 2015 [2]. The report also shows that in 2015 only $3 \%$ of the candidates got a distinction $(80 \%$ and above). This situation does not resonate with the developmental initiatives of the government to address the skills shortage in science, engineering and technology in the country and enhance its competitiveness in the global economy.

The students' poor achievement in mathematics can be attributed to teachers' teaching practices. Many students do not enjoy learning mathematics because they find it uninteresting and boring. Many research studies are of the view that ICTs can support mathematics teaching and learning and make the students' mathematics learning more meaningful and joyful [3]. Thambi and Eu advocate the integration of technology into mathematics teaching and learning because it helps students to visualize how any changes in one variable affects others thereby enhancing their learning experience compared to just manipulation of formulae to get the answer [4].

ICT can stimulate, motivate and spark students' appetites for learning and helps to enhance academic achievement $[5,6]$. This can be demonstrated in their increased commitment to the learning task, increased independence and motivation for self-directed study, their enhanced enjoyment, interest and sense of achievement in learning when using ICT, and their enhanced self-esteem [7]. ICT, according to Mohanty, can be used to provide challenging and authentic content that will engage the students in the learning process [8]. Similarly, [9] observed that ICT might offer students tools for knowledge construction, reflecting, knowledge sharing and collaboration. These will lead to increased students' learning and achievement.

\section{Background}

A function in mathematics is a rule or relationship for which any input value results in one unique output [10]. Functions are classified according to their degree, which is the highest power of the variable, or by the type of graph that the relationship gives. Functions are one of the topics that has been highlighted in previous diagnostic reports as a topic where learners achieve low marks in the final matric examinations [2]. This might be a result of commonly used traditional teaching methods which are not promoting learner understanding.

The basis of the topic (functions) lies in linear functions and their graphs which are taught in the senior phase (Grade 7-9). There is content progression as learners go 
through the Further Education and Training band (Grade 10-12) and the examination assesses on concepts from lower grades. Most schools are still using the chalkboard methods which make the process of teaching and learning of functions a very difficult one. This could have the implication that both the educators and the learners could develop a dislike for the subject. The topic on functions contributes a considerable percentage in the Grade 12 school certificate mathematics examination.

In the South African school system, functions are introduced from the lower grades when learners start exploring the relationships between variables, but we meet the notion of a linear function in the senior phase (Grades 7-9) in the South African Curriculum and Assessment Policy Statement (CAPS) [11]. The focus of the study was on interpreting and drawing graphs in Grade 9. Learners are expected to revise work covered in Grade 8, on interpreting graph concepts; which include analysing and interpreting global graphs of situations, linear or non-linear graphs, decreasing or increasing as well as maximum or minimum. The learners are also expected to extend these concepts with special focus on drawing linear graphs from given equations and determining the equation of a linear function from linear graphs, and determine the x-intercept, the $y$ intercept and the gradient.

The teaching of linear functions in Grade 9 was the focus of the study, because if learners who do not understand the linear functions in Grade 9 they will likely progress to Further Education and Training band (Grades 10-12) with misconceptions of the notion. The learners might also end up opting not to do mathematics in Grade 10. The topic of functions is flexible enough to allow the introduction of other teaching methods such as technology-based approaches, in particular GeoGebra, which facilitates exploration, representation and analysis of functions among other things.

The focus of evaluation in CAPS nowadays has shifted from just asking learners to plot graphs of functions to the analysis and applications that learners are able to perform using available information on graphs [11]. Therefore, integrating the GeoGebra with the teaching and learning of linear functions will enable learners to explore and develop schemas which enable them not only to plot graphs of functions, but to answer higher order questions which also enable them to analyse, reflect and apply acquired knowledge.

The use of functions to solve authentic real life situations has elevated the topic of linear functions to being the base of decision making. Learners are sometimes called upon to translate real-life situations into graphs in order to come up with feasible and fruitful solutions, and that could be achieved if the learners have acquired the necessary mind concepts and schemas in linear functions to equip them and enable them to tackle such problems.

The Mopani district in the Limpopo province of South Africa has over a hundred schools with most of them being rural no-fee schools. In general, most learners in the Limpopo schools are from under-privileged backgrounds. Textbooks and some computers were made available to schools. Recently, various stakeholders, who include government, invested in making computers and some graphing software available to schools, but these computers are not being used in the teaching and learning process, but are lying idle or being used for administrative purposes. This issue of computers not being utilized for teaching and learning made it imperative that the researchers 
investigate the effect of integrating GeoGebra in the teaching of linear functions on Grade 9 learners' achievement in the Mopani district. This study aimed at providing answers to the following question: is there any difference in the achievement scores of learners exposed to GeoGebra as compared to the learners who were not exposed to GeoGebra in learning linear functions?

\section{Theoretical framework}

This study was guided by the constructivist theory of learning which advocates that knowledge is constructed in an individual's mind by active participation in certain experiences [12]. The basic belief of the constructivists is that students actively construct knowledge, contrary to the view that knowledge is transmitted by the educator $[13,14]$; students are viewed as active constructors of knowledge rather than passive recipients [12]. Constructivists make a distinction between cognitive and social constructivism. Social constructivists are of the notion that knowledge is a result of collaborative construction in a socio-cultural context and that learning is fostered through information sharing, negotiation and discussions [15]. Hence, social constructivists put emphasis on the learning environment that must provide for easy communication and collaboration with others $[15,16]$. To the cognitive constructivists learning is primarily an individual affair hence pedagogical design should support and satisfy the needs of individual students to create knowledge [17]. Despite the varied theoretical perspectives of constructivism leading to many definitions of constructivism, the varied theoretical perspectives have the common characteristics that knowledge is constructed and not passively absorbed [18] and emphasise student-centred instructional approach [19].

This study focused on the effects of the integration of GeoGebra into the teaching of linear functions on the students' achievement. In consonance with constructivist theories, it is believed that the technology can help students construct and understand mathematical knowledge. The mathematical understanding will eventually translate to improved achievement in mathematical exercise.

The technology could stimulate the student to go through the series of actions and processes so as to objectively construct their own schemas. The students continue to go backwards and forward as they construct their own knowledge, based on the experience provided by the technology. It can promote the development of an inquisitive mind which seeks to explore and achieve a deeper understanding of the concepts being learnt.

\section{GeoGebra}

GeoGebra is dynamic mathematical software for all levels of education that joins arithmetic, geometry, algebra and calculus [20]. According to [21], GeoGebra is a software package that combines both geometry and algebra and that is specifically designed for educational purposes and can help learners to foster their mathematical learning. GeoGebra is interactive software which can be used to draw points, vectors, lines, conic sections as well as functions while allowing equations and coordinates to be entered directly. Thus it is possible to use GeoGebra when working with numbers for vectors 
and points. An expression written in the algebra view corresponds to an object in the graphics view. Furthermore, it is free and available for use both at school and at home, providing great opportunities to learners doing their homework. GeoGebra can also help in lessons and activities aligned with the standards, goals and objectives of CAPS. Furthermore, GeoGebra with its multiple features of dynamic modelling contributes widely to improving learners' general perception of mathematics and is relatively easy to use by beginners. The biggest advantage of using GeoGebra is that it is user-friendly as learners can navigate and can assess their own work.

GeoGebra can foster active student-centred problem-solving by allowing for mathematical experiments, interactive explorations, as well as discovery teaching [22]. In a study in Turkey, Akgül found that GeoGebra-assisted instruction had a significant positive effect on the students' achievement in transformation geometry and geometric thinking when compared to the chalk and talk method [23].

In a study on the effectiveness of using GeoGebra software on mathematics learning among students in Malaysia, Arbain and Shukor found that GeoGebra had a positive impact on students' achievement, confidence and motivation to learn [24]. Similarly, Ocal investigated the effect of Geogebra assisted instruction on students' achievements regarding their conceptual and procedural knowledge of the applications of derivative in Turkey [25]. The study found that instruction with Geogebra had a positive effect on students' achievements regarding conceptual knowledge, suggesting that Geogebra supported students meaningfully learning of the subject.

Some other studies have found the integration of Geogebra with the teaching and learning of some concepts and topics in mathematics effective in enhancing students' learning and achievement $[26,27,28]$.

\section{$5 \quad$ Methodology}

The researchers used the pre-test post-test, control group design with two groups. One group was the experimental group and the other group was the control group. This design, involved "at least two randomly formed groups, both groups are pre-tested, one group receives a new or unusual treatment and both groups are post-tested" [29].

\subsection{Participants}

The participants were 62 Grade 9 learners from two schools in a circuit in the Mopani district. The sampling of the participants was done using multi-stage sampling. The selection of the circuit from the ten circuits in the Mopani district was purposive and chosen for its availability and convenience to the researchers. Sampling of the participating schools in the circuit was random. The Grade 9 classes at the participating schools were selected as intact classes for the study. School A, which had 29 learners, was the control group and school B with 33 learners was the experimental group. 


\subsection{Data collection instrument}

The study used an achievement test. The test questions were compiled by the first author in collaboration with other mathematics educators in the circuit. The test was administered as the pre-test at the beginning of the intervention and also as a post-test at the end of the intervention. The test consisted of nineteen sub-questions in five questions that assessed the learners' knowledge of linear functions as stipulated in the Curriculum Assessment Policy Statement (CAPS). For instance, the CAPS document stipulates that learners should be able to sketch and compare the graphs of linear equations, investigate gradients by comparing the ratio of vertical change to horizontal change between any two points on a straight line graph and determine the equation of the straight line passing through two points.

\section{$5.3 \quad$ Validity}

To ensure that the test was valid, the questions were developed in line with the CAPS curriculum for Grade 9. The test questions were compiled by the first author in collaboration with mathematics educators to ensure that they were in line with the cognitive demand of the content of Grade 9 linear functions according to the curriculum. After developing the questions, they were given to curriculum advisors and to the mathematics committee in the circuit to rate if they were relevant and also conform to the curriculum requirements. They confirmed that they found all the questions relevant for the purpose.

\subsection{Reliability}

Reliability was ascertained using the Kuder-Richardson (KR-20) test which according to McMillan and Schumacher is a type of internal consistency check for questions that are marked right or wrong [30]. It is a special case of Cronbach's alpha that measures reliability for dichotomous data. KR-20 was conducted using SPSS which performs the test in a similar way to Cronbach's alpha except that KR-20 is case specific and is used to test the reliability of test questions. The reliability coefficient measures the likelihood of obtaining similar results if the test is administered to another set of different learners and the results range from $0-1$. A result greater than 0.5 on a teacher-made test can be considered as having good internal consistency although the higher the result the better the internal consistency of the test or exam [31].

\subsection{Data analysis}

The data collected from the pre-test and the post-tests was analysed using descriptive and inferential statistics. Descriptive statistics involved describing the pre-test and posttest data giving the mean, standard deviation, range and so on. Inferential statistics was done using the t-test. The t-statistic was calculated at a 5\% confidence level using a 2tailed test and used to test the null hypothesis for this study. 


\section{$6 \quad$ Findings}

A pre-test was administered to both the control group (Group A) and the experimental group (Group B) and the summary of the descriptive statistics for the results are shown in Table 1.

Table 1. Descriptive statistics of pre-test achievement

\begin{tabular}{|l|c|c|c|c|}
\hline & N & Mean & Std. Dev. & Std. Error Mean \\
\hline Control & 29 & 4.41 & 2.797 & .519 \\
\hline Experimental & 33 & 4.30 & 3.359 & .585 \\
\hline
\end{tabular}

The control group had 29 participants while the experimental group had 33 participants. The mean scores of the control and experimental groups were 4.41 and 4.3 respectively. An independent sample t test was conducted to determine whether there was a statistically significant difference between the pre-test mean scores of the two groups at a $5 \%$ level of significance. The results are presented in Table 2 .

Table 2. Independent Samples t- Test of the Pre-test Results

\begin{tabular}{|c|c|c|c|c|c|c|c|c|c|}
\hline \multirow{3}{*}{$\begin{array}{l}\text { Pretest \% } \\
\text { score }\end{array}$} & \multicolumn{2}{|c|}{$\begin{array}{l}\text { Levene's test } \\
\text { for equality } \\
\text { of variances }\end{array}$} & \multicolumn{7}{|c|}{ t-test for Equality of Means } \\
\hline & \multirow[t]{2}{*}{$\boldsymbol{F}$} & \multirow[t]{2}{*}{ Sig. } & \multirow[t]{2}{*}{$t$} & \multirow[t]{2}{*}{$d f$} & \multirow[t]{2}{*}{$\begin{array}{l}\text { Sig. (2- } \\
\text { tailed) }\end{array}$} & \multirow[t]{2}{*}{$\begin{array}{c}\text { Mean } \\
\text { Diff. }\end{array}$} & \multirow{2}{*}{$\begin{array}{l}\text { Std. } \\
\text { Error } \\
\text { Diff. }\end{array}$} & \multicolumn{2}{|c|}{$\begin{array}{l}95 \% \text { Confidence } \\
\text { Interval of the Dif- } \\
\text { ference }\end{array}$} \\
\hline & & & & & & & & Lower & Upper \\
\hline $\begin{array}{l}\text { Equal variance } \\
\text { assumed }\end{array}$ & .339 & .563 & .140 & 60 & .889 & .111 & .791 & -1.472 & 1.694 \\
\hline $\begin{array}{l}\text { Equal variance } \\
\text { not assumed }\end{array}$ & & & .142 & 59.84 & .888 & .111 & .782 & -1.454 & 1.675 \\
\hline
\end{tabular}

For the results in Table 2, Levene's test statistic is 0.563 which is greater than 0.05 , therefore the assumption of equal variances is upheld and hence the group variances are assumed to be equal. Therefore, the $\mathrm{p}$ value (sig. 2-tailed) for the t-test for the equality of means is 0.889 , implying that the difference in the means is not statistically significant at 0.05 level. The results showed that there is no statistically significant difference $(p>0.05)$ between the mean scores of the two groups based on their pre-test results. It statistically indicates that learners in both groups had comparable achievement levels at the beginning of the intervention. Any difference observed thereafter may be attributed to the use of GeoGebra.

The results of the post-test were analysed using the t-test in SPSS and used to answer the research question.

A comparison of the control group and experimental group post-test results shows that the minimum score in the control group was $6 \%$ and the maximum score was $50 \%$, while the minimum score in the experimental group was $18 \%$ and the maximum score 
was $86 \%$. These results indicate that the learners in the experimental group achieved higher scores than those in the control group

Table 3 also shows a comparison of the group statistics for the t-test between the control group and the experimental group.

Table 3. Descriptive statistics of post-test achievement

\begin{tabular}{|l|c|c|c|c|}
\hline & N & Mean & Std. Dev. & Std. Error Mean \\
\hline Control & 29 & 20.00 & 11.161 & 2.073 \\
\hline Experimental & 33 & 51.76 & 17.950 & 3.125 \\
\hline
\end{tabular}

Table 3 shows that 62 learners participated in the post-test. The control group had a mean score of twenty, standard deviation of 11.161 and standard error of 2.073, while the experimental group had a mean score of 51.76, standard deviation of 17.95 and standard error of 3.125. The learners in the experimental group achieved higher scores than the learners in the control group. Table 4 shows the results of the independent samples t-test.

Table 4. Results of the independent samples t-test of post-test

\begin{tabular}{|c|c|c|c|c|c|c|c|c|c|}
\hline \multirow{3}{*}{$\begin{array}{l}\text { Post-test \% } \\
\text { score }\end{array}$} & \multicolumn{2}{|c|}{$\begin{array}{c}\text { Levene's test } \\
\text { for equality of } \\
\text { variances }\end{array}$} & \multicolumn{7}{|c|}{ t-test for Equality of Means } \\
\hline & \multirow[t]{2}{*}{$F$} & \multirow[t]{2}{*}{ Sig. } & \multirow[t]{2}{*}{$t$} & \multirow[t]{2}{*}{$d f$} & \multirow[t]{2}{*}{$\begin{array}{l}\text { Sig. (2- } \\
\text { tailed) }\end{array}$} & \multirow[t]{2}{*}{$\begin{array}{l}\text { Mean } \\
\text { Diff. }\end{array}$} & \multirow{2}{*}{$\begin{array}{l}\text { Std. } \\
\text { Error } \\
\text { Diff. }\end{array}$} & \multicolumn{2}{|c|}{$\begin{array}{l}\text { 95\% Confidence } \\
\text { Interval of the } \\
\text { Difference }\end{array}$} \\
\hline & & & & & & & & Lower & Upper \\
\hline $\begin{array}{l}\text { Equal variance as- } \\
\text { sumed }\end{array}$ & 5.01 & .029 & -8.22 & 60 & .000 & -31.76 & 3.860 & -39.478 & -24.037 \\
\hline $\begin{array}{l}\text { Equal variance not } \\
\text { assumed }\end{array}$ & & & -8.47 & 54.33 & .000 & -31.76 & 3.750 & -39.274 & -24.241 \\
\hline
\end{tabular}

For the results in Table 4 Levene's test statistic is 0.029 , which is less than 0.05 , therefore we ignore the assumption of equal variances and hence the group variances are not assumed to be equal. Therefore, the $\mathrm{p}$ value (sig. 2-tailed) for the t-test for the equality of means is less than 0.05 , implying that the difference in the means is statistically significant at the 0.05 level. These results indicate that the learners in the experimental group achieved higher scores in linear functions than the learners in the control group. Hence, based on the findings from the t-test analyses we can reject the null hypothesis (There is no statistically significant difference in the achievement scores of learners exposed to the GeoGebra software and those not exposed to the GeoGebra software) in favour of the alternative hypothesis (There is a statistically significant difference in the achievement scores of learners exposed to the GeoGebra software and those not exposed to the GeoGebra software).

Furthermore, Table 5 shows the measures of association between the total percentage score and the treatment. 
Table 5. Measures of Association

\begin{tabular}{|l|c|c|}
\hline & Eta & Eta Squared \\
\hline Total \% Score * Treatment & .728 & .530 \\
\hline
\end{tabular}

Table 5 shows that the effect size $($ Eta squared $=0.53)$ which shows the proportion of variance of the learners' achievement which is explained for by the treatment [32]. This means that $53 \%$ of variation in the achievement is as a result of the treatment which was used; in this case the use of GeoGebra to teach linear functions.

\section{$7 \quad$ Discussion of findings}

The post-test result showed that there was a statistically significant difference in the achievement of the learners in the experimental group compared to those in the control group with regard to achievement in linear functions. From the findings of the study, it is evident that the learners who were exposed to GeoGebra (experimental group) achieved better in linear functions compared to those who were not exposed to GeoGebra (control group). Hence, this finding suggests that the use of GeoGebra in the teaching and learning of linear functions enhanced learners' performance and achievement in linear functions. This finding is in line with the findings of Ocal, Shadaan and Leong on the effectiveness of GeoGebra in teaching and learning mathematics of $[25,28]$. Furthermore, the findings of this study agree with Ogbonnaya and Mji that the use of graphing software enhanced learners' achievement in hyperbolic functions [33]. In this case GeoGebra enhanced the learning of linear functions. The findings also support earlier findings by Aydos, Ogbonnaya, and Chimuka that GeoGebra enhances learners' achievement in mathematics $[34,35,36]$.

The learners in the experimental group were exposed to a new innovative way of learning linear functions through the use of GeoGebra, which most likely captured their attention and interest during mathematics lessons. In line with the finding of Hohenwarter and Jones, the interactive and dynamic nature of GeoGebra allowed the learners in the experimental group to draw, compare, and analyse the linear graphs with ease [21]. They were also afforded the opportunity to explore linear functions, alone or with their peers which enabled them to better understand the notion of linear functions. The learners in the experimental groups could also check and assess the correctness and accuracy of their own without having to wait for the educator. They could also draw and analyse several graphs at the same time without having to go through the tiresome process of sketching the graphs, therefore, while using GeoGebra the learners had more time to answer higher order questions and this could have contributed towards the higher achievement scores in the experimental group.

This may also be attributed to the fact that learners in rural schools usually have problems of communicating between themselves or with the educators using the language of learning and teaching, therefore the learners in the experimental group were afforded with an option to break the barrier since they no longer needed to rely on language to communicate. GeoGebra shifted the learners from relying solely on the educator during the lessons, because they could now answer more questions than the 
ones provided by the educator, which implied more practice and ultimately more clarity for the learners. They could now interact and explore concepts on their own or with peers. In other words, GeoGebra enhanced learners' curiosity and inquisitiveness.

The findings of this study show that use of GeoGebra in teaching and learning mathematics enhanced learners' achievement in linear functions. These findings have wide implications for teaching and learning mathematics. Hence, the researchers recommend that educators should integrate GeoGebra into their teaching activities, since it has proved to be effective in enhancing achievement. By shifting the learners' efforts from the tedious task of drawing the graphs manually, the software allowed them to focus on other relevant issues such as exploration and making sense of linear functions and creating their own understanding of the concepts.

Before the study, the researchers, in interactions with other mathematics teachers, found that not many of them were able to manipulate and use GeoGebra software effectively due to a lack of adequate orientation. Cashman and Gunter asserted that, if integrated properly, digital media also have the capability to stimulate imagination and develop critical thinking skills while allowing students to take an active role in their own learning [37]. They went on to say that teachers need to be well prepared in the aspects of the Technology Pedagogical Knowledge Kit in order to be able to facilitate learning in an ICT integrated learning environment, and introducing ICTs in isolation can have harmful effects which may result in educators shying away from technology use. The researchers thus recommend that the software should be followed up with training on the use of the software. Training workshops are a crucial element for teachers to enable them to integrate the software as part of their teaching process. The schools should also be supplied with more computers in order to decrease the learner to computer ratios in schools since teachers dread having to plan for a lesson with many learners sharing a computer as it becomes difficult to maintain the effectiveness of the lesson when learners are in large groups.

The department of education should upgrade the available resources at schools to provide them with online access such as the Gauteng online project to enable the teachers and learners access to information online. GeoGebra is dynamic software that allows users to confer with other users on the GeoGebra wiki and user forum. Thus, teachers can access help and upgrade themselves instead of having to rely solely on the workshops provided by the department.

GeoGebra proved to be an effective tool in teaching linear functions to Grade 9 learners in the Mopani district. The researchers thus make the recommendation that teachers should adopt the software to teach mathematics as it is user friendly and it allows them to plan effectively for their lessons. GeoGebra was used in Grade 9 but can be extended to teach many other concepts across the different grades. It can also be used to teach several other topics in the CAPS curriculum. Hence, its relevance in the mathematics classroom has no limits.

Teachers should make use of the dynamic nature of the software to capture learners' interest and to keep them motivated. The software provides the learners with a platform where they can explore and test ideas as they build their own structures about concepts, and the interactive nature of GeoGebra will activate the inquisitive nature of their minds and prompt them to be more exploratory in their learning. 
Teachers and other people involved in education should carry out more studies on the use and effectiveness of the GeoGebra software as it will iron out issues in education, especially in mathematics. Further research will enable the identification of problem areas as well as provide the means to solve those issues. It also provides them with new knowledge.

\section{Conclusions}

In this study, using GeoGebra to teach linear functions resulted in higher achievement scores in the experimental groups. It proved to be more effective in enhancing learners' achievement, particularly on the topic of linear functions. The hands on and interactive approach of the software had a positive effect and it enabled learners to understand concepts much better than the learners who were not exposed to the software. A statistically significant result for both experimental groups compared to the control groups also serves to add weight to the results from previous studies (e.g. on the effectiveness of GeoGebra software on learner achievement) [24, 26, 38].

\section{Limitations of the study and recommendations for future study}

The limitation of this study is that learners' achievement was measured by the marks obtained on the test only, while not addressing other factors that are needed for learners to achieve, such as motivation.

The study focused on one topic (linear functions) and on Grade 9 only to investigate the effect of integrating GeoGebra in the teaching and learning of linear functions on Grade 9 learners' achievement. Therefore, generalizing the findings of this study to other topics in mathematics and other grade levels should be done with caution. The study was also conducted in the Mopani District only, with two schools, so repeating the study in a different place with different learners might not produce similar findings.

This study can act as a stepping stone for further research. For instance, studies can be done to investigate how to make use of the learners' smartphones to integrate the GeoGebra software as part of the learning of mathematics in a variety of situations within the classroom and outside the classroom.

Further research should be conducted on the effectiveness of GeoGebra in teaching and learning mathematics in other levels of learning and to teach other topics in mathematics, even in other learning areas.

The researchers further recommend qualitative studies to assess the learners' perceptions towards the use of GeoGebra and other software in learning mathematics. The studies should also assess educators' attitudes and perceptions towards the use and integration of ICTs into the teaching of mathematics 


\section{References}

[1] R, Pierce, "Linear functions and a triple influence of Teaching on the development of students' algebraic expectation," Int. Group for the Psych. Math. Educ.," Vol 4, pp. 81-88. 2005.

[2] Department of Basic Education. "Schools Subject and Diagnostic Report". 2015. [Online]. Available from: https://www.education.gov.za/Resources/Reports.aspx. Accessed on 16 September 2018.

[3] B. Means and G. Haertel, "Using Technology Evaluation to Enhance Student Learning," New York: Teachers College Press. 2004.

[4] N. Thambi and L. K. Eu. "Effect of Students' Achievement in Fractions using GeoGebra," SAINSAB, Vol. 16, pp. 97-106. 2013.

[5] S. A. Elian and D. A. Hamaidi. "The Effect of Using Flipped Classroom Strategy on the Academic Achievement of Fourth Grade Students in Jordan," International Journal of Emerging Technologies in Learning, Vol. 13, No. 2, pp. 110-125. 2018. https://doi.org/10.3991/ijet.v13i02.7816

[6] W. Koch, J. Schachenreiter, K. Vogt, G. Koch and W. Göderle. "Teaching Technology Usage in the ENT Medical Subdomain via a Flipped Classroom Approach," International Journal of Advanced Corporate Learning, Vol. 11, No., 1, pp. 31-35. 2018. https://doi.org/10.3991/ijac.v11i1.9105

[7] The British Educational Communications and Technology Agency [BECTA, "Harnessing Technology: Next Generation Learning” Coventry. BECTA, 2008.

[8] O. I. Ikwuka, and J. E. Adigwe, "Effect of ICT on Secondary School Students' Academic Performance in Christian Religious Studies in Oshimili North Local Government Area," Int. J of Innovative Sci, Eng \& Tech. Vol. 4 No 5, pp. 376-384, 2017

[9] C. Zhou, A. Purushothaman and N. Rongbutsri. "Facilitating Sustainability of Education by Problem-Based Learning (PBL) and Information and Communication Technology (ICT)," International Journal of Emerging Technologies in Learning, Vol. 8, No. 6, pp, 50-54. 2013. https://doi.org/10.3991/ijet.v8i6.3146

[10] M. Chitsike, "Spot on Mathematics: Learners Book. Grade Eight," Pearson Publishers, 2013.

[11] Department of Basic Education "Curriculum and Assessment Policy Statement," 2012. Retrieved from: https://www.education.gov.za/Curriculum/CurriculumAssessmentPoli cyStatements(CAPS).aspx

[12] M. D. Roblyer, and A. H Doering. "Integrating educational technology into teaching," (fourth edition.) Columbus, Ohio: Merrill Prentice Hall. 2006

[13] Q. Wang, "A Generic Model for Guiding the Integration of ICT into Teaching and Learning," Innovations in Educ. and Teaching Int. Vol. 45 No. 4, pp. 411-419 2008 https://doi.org/10.1080/14703290802377307

[14] A. Hirumi, "A Framework for Analysing, Designing and Sequencing Planned e-Learning Interactions: A Grounded Approach," Int. J. on E-Learning, Vol. 1 No. 1, pp. 19-27, 2002.

[15] P. Eggen and D Kauchak, "Educational psychology: windows on classroom," (eight edition). London: Pearson Education, Inc. 2010

[16] R. J. Amineh and H. D. Asl. "Review of constructivism and social constructivism," J. of Soc. Sci., Lit. and Languages. Vol. 1 No. 1, pp. 9 -16. 2015

[17] G. W. Maxim, "Dynamic Social Studies for Constructivist Classrooms," (eight edition). Upper Saddle River, NJ: Pearson. 2006.

[18] N. Z. Amarin and R. I. Ghishan, "Learning with technology from a constructivist point of view," International Journal of Business, Humanities and Technology, vol 3 No. 1, pp. 5257. 2013.

[19] R. E. Slavin and N. Davis, "Educational Psychology: Theory and Practice,” East Montpelier: Johnson State College, 2006.

[20] M. Hohenwarter and K, Fuchs, "Combination of dynamic geometry, algebra and calculus1 in the software system GeoGebra," In Comput. Algebra Syst. And Dynamic Math. Teaching Conf. 2004. 
[21] M. Hohenwarter and K. Jones, "Ways of Linking Geometry and Algebra, the case of GeoGebra," Proc. of the Brit. Soc. for Res. into learning Math. Vol. 27 No. 3, pp. 126-131, 2007.

[22] T. Prodromou, "GeoGebra in teaching and learning introductory statistics," The Turkish $J$. of Educ. Technol. Vol. 8 No. 2, pp. 53-67, 2015.

[23] M. B. Akgül, "The effect of using dynamic geometry software on eight grade students' achievement in transformation geometry, Geometric thinking and attitudes toward mathematics and Technology." Unpublished Master's dissertation, Middle East Technical University, Ankara Turkey. 2014. [Online] Available from: http://etd.lib.metu.edu.tr/upload/12616880/index.pdf. Accessed on 2 August 2018. https://doi.org/10.1016/j.sbspro. 2015.01 .356

[24] N. Arbain and N. A. Shukor, "The effects of GeoGebra on students' achievement," Procedia - Soc. Behav. Sci. Vol. 172, pp. 208 - 214. 2015.

[25] M. F. Ocal, "The Effect of Geogebra on Students' Conceptual and Procedural Knowledge: The Case of Applications of Derivative," "Higher Educ. Studies", Vol. 7 No. 2, pp. 67-78. 2017. https://doi.org/10.5539/hes.v7n2p67

[26] Z. A. Reis and S. Ozdemir. "Using Geogebra as an information technology tool: Parabola teaching," Procedia-Soc. Behav. Sci., 9, 565-572.2010.

[27] R. Saha, A. F. Ayub and R. A. Tarmizi, "The effects of GeoGebra on Mathematics achievement: Enlightening coordinate geometry learning," Procedia Soc. Behav. Sci. Vol. 8, pp. 686-693.2010. https://doi.org/10.1016/j.sbspro.2010.12.095

[28] P. Shadaan and K.E. Leong, "Effectiveness of using GeoGebra on students' understanding of circles," Malaysian Online J. Educ. Technol. Vol. 4 No. 1, pp. 1-11

[29] G. E. Mills and L. R. Gay, "Educational research: Competencies for analysis and applications," New York: Pearson Education International, 2016.

[30] J. H. McMillan and S. Schumacher, "Research in Education: Evidence-Based Inquiry," London. Pearson Publishing, 2014.

[31] M. Tavakol and R. Dennick, R. "Making sense of Cronbach's Alpha," Int. J. Med. Educ. Vol. 2, pp. 53-55.2011. https://doi.org/10.5116/ijme.4dfb.8dfd

[32] J. Pallant, J. "SPSS survival manual, a step by step guide to data analysis using SPSS for windows (version 10 and 11," 2001. [Online] Available from: https://lwn98mqek01.storage.googleapis.com/QjAwME9VWDNEMg==01.pdf. Accessed on 27 August 2018.

[33] U. I. Ogbonnaya and A. Mji, A., "Enhancing students' learning of hyperbolic functions by the use of Information and Communication Technol. (ICT)," In Proc. of 5th annual Int. Conf. Educ. and New Learning Technol. (Edulearn), Barcelona-Spain, pp. 5619 -5326 2013

[34] M. Aydos, "The Impact of Teaching Mathematics with GeoGebra on the Conceptual Understanding of Limits and Continuity: The Case of Turkish Gifted and Talented Students," İhsan Doğramac1 (Doctoral Dissertation, Bilkent University. 2015.

[35] U. I. Ogbonnaya, "Improving the Teaching and Learning of Parabolic Functions by the use of Information and Communication Technology (ICT)," African J. of Res. Math. Sci. Technol. Educ. Vol. 14 No. 1, pp. 49-60. 2010

[36] U.I. Ogbonnaya and A. Chimuka, A. "Joyful learning of mathematics using GeoGebra," Proc. of 8th Annu. Int. Conf. Educ. and New Learning Technol. (Edulearn), BarcelonaSpain, 4-6 July, 2016. pp. 4301-4307 2016.

[37] S. Cashman and G. Gunter "Integrating technology and digital media in the classroom" Boston: Thompson Course Technology. 2008.

[38] E. Z. Hutkemri "Impact of using GeoGebra on Students' Conceptual and Procedural Knowledge of Limit Function,” Mediterranean J. of Soc. Sci., Vol. 5 No. 22, pp. 873-881. 2014. https://doi.org/10.5901/mjss.2014.v5n23p873

\section{Authors}

Melody Mushipe is a mathematics educator and a post graduate student in mathematics education at Institute for science and technology Education, University of South 
Africa, South Africa. Her research interest is on use of software technologies in teaching and learning mathematics (e-mail: chicco23melo@yahoo.com).

Ugorji I. Ogbonnaya is a lecturer in mathematics education at University of Pretoria, South Africa. His research interest includes the use of technology in teaching and learning of mathematics.

Article submitted 2018-09-23. Resubmitted 2018-11-29 and 2019-01-03. Final acceptance 2019-01-10. Final version published as submitted by the authors. 